\title{
CHRONIC BERYLLIUM POISONING
}

\author{
BY \\ J. WARREN JORDAN AND CHRISTOPHER S. DARKE \\ From the Chest Clinic, Pontefract, and the City General Hospital, Sheffield
}

(RECEIVED FOR PUBlication JANUARY 7, 1958)

In 1933 Weber and Engelhardt reported the first case of acute pneumonitis due to beryllium poisoning. Other instances of the acute reaction to beryllium salts were described by Van Ordstrand, Hughes, DeNardi, and Carmody (1945). Hardy and Tabershaw (1946) gave details of the chronic or delayed form of the disease, and DeNardi, Van Ordstrand, Curtis, and Zielinski (1953) published a review of 468 cases of beryllium disease of all clinical types. Only three cases with chronic lung disease have so far been reported in Britain (Agate, 1948 ; Sneddon, 1955 ; Rogers, 1957). This report describes a patient who suffers from chronic beryllium poisoning and discusses the various criteria by which a diagnosis is made.

\section{Case Report}

The patient, an unmarried woman, was born in 1910 , and was first seen in October, 1955, because of a chronic cough and finger clubbing. She left school at 14 years and was employed as a baker for five years. She had to leave this work as her skin became sensitized and for the next 11 years remained at home. The patient then began clerical work in a tailoring stores. This was interrupted from June, 1943, until May, 1945, when she worked in a factory making fluorescent lamps. At the time, zinc beryllium silicate phosphors in high concentration were used in the manufacture of these lamps. The patient's work consisted in placing the tubes on horizontal metal rollers. The solution containing beryllium was baked on the inner surface of the tubes, and, after cooking, the tubes were removed from the oven and about 2 in. of deposit was extracted from each end of the tube with a rubber-padded brush. Very little dust was released in the process, as the ends of the tube were enclosed in a box covering. Tubes were broken from time to time and the patient received some small lacerations from these. During the whole of this period she felt quite well and no medical or radiological examination was made.

In 1945 she went to live in a small town far removed from that in which she did her factory work. She started clerical work again and continues at this occupation.

A few years later a gradual deterioration in her health was noticeable and she found that she was unable to take long country walks because of short- ness of breath. In 1950 an unproductive cough and vague chest pains developed and clubbing of the fingers was first observed by the patient. During the next five years the cough became more severe but remained unproductive. It was continuous throughout the year although worse in the winter months and more marked during the day than at night. The chest pain was situated deep to the lower sternum and in the left inframammary region, radiating to the left scapula. It was dull and prolonged in character, occurring both at rest and during activity, and became increasingly severe. The patient lost a great deal of weight during this period. -A poor appetite and general malaise were only marked during the previous 12 months. There was no haemoptysis, sweating, vomiting, or diarrhoea. No relevant past history or family history was obtained.

Clinical Findings.-The patient was an alert, active, and cheerful individual with a tendency to minimize her symptoms. Her height was $4 \mathrm{ft}$. 9 in. $(144 \mathrm{~cm}$.) and weight $6 \mathrm{st}$. $4 \mathrm{lb}$. (40 kg.). There was moderate clubbing of the fingers and toes. There was no cyanosis but tachypnoea was present at rest. Chest expansion measured 1 in. The percussion note was resonant. The breath sounds were vesicular and of equal intensity over both lungs. Persistent rales and occasional coarse rhonchi were also audible over both lung bases.

The heart was normal except for accentuation of the pulmonary component of the second sound. The tip of the spleen could be felt on full inspiration. The liver was not enlarged, but the epitrochlear and axillary lymph nodes were slightly enlarged. The tibiae were considerably bowed from old rickets.

SkIN Lesions.-Small scars were present on the extensor surface of the left forearm, over the right knee and both ankles (Fig. 1). They measured $\frac{1}{2}-1$ in. in length and were flat or slightly depressed and reddish purple. They were the result of trivial cuts from broken fluorescent tubes and had existed unchanged for at least 10 years.

INVESTIGATIONS. - A chest radiograph showed patchy, dense shadowing throughout both lung fields obscuring the vascular pattern (Fig. 2). There appeared to be a background of diffuse coarse nodular shadows as well as areas of massive fibrosis. Radiological examination of the hands was normal.

The Mantoux test was negative to 10 T.U. of old tuberculin. White cells numbered 11,000 per c.mm. 

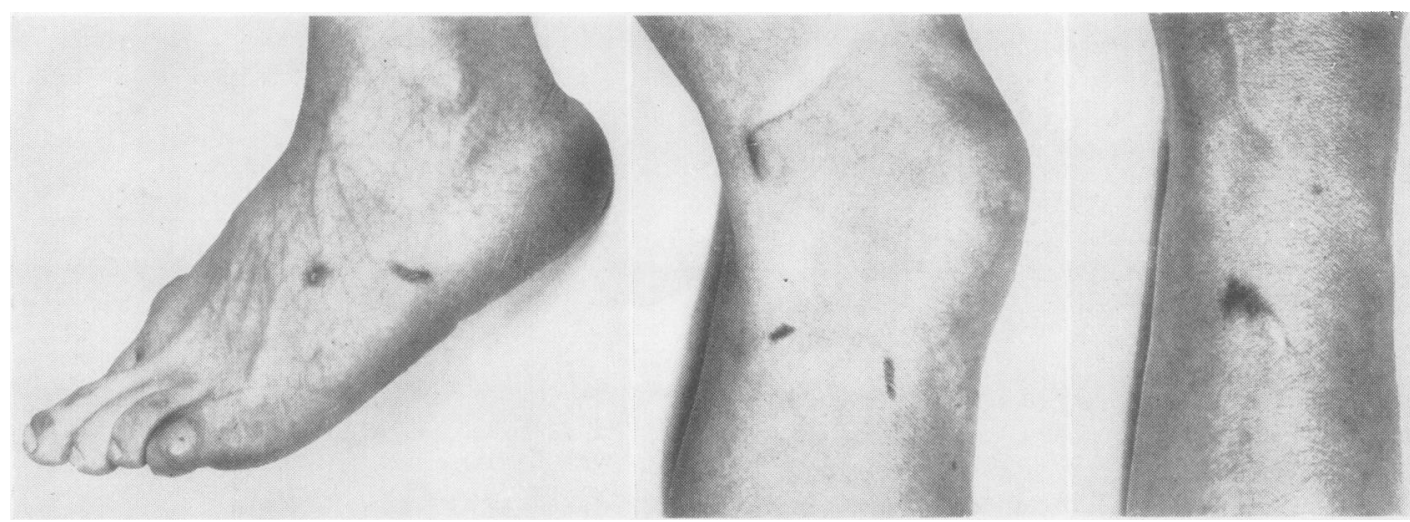

Fig. 1.-Left foot, right knee, and left forearm showing skin lesions resulting from lacerations with glass coated with zinc beryllium silicate phosphors.

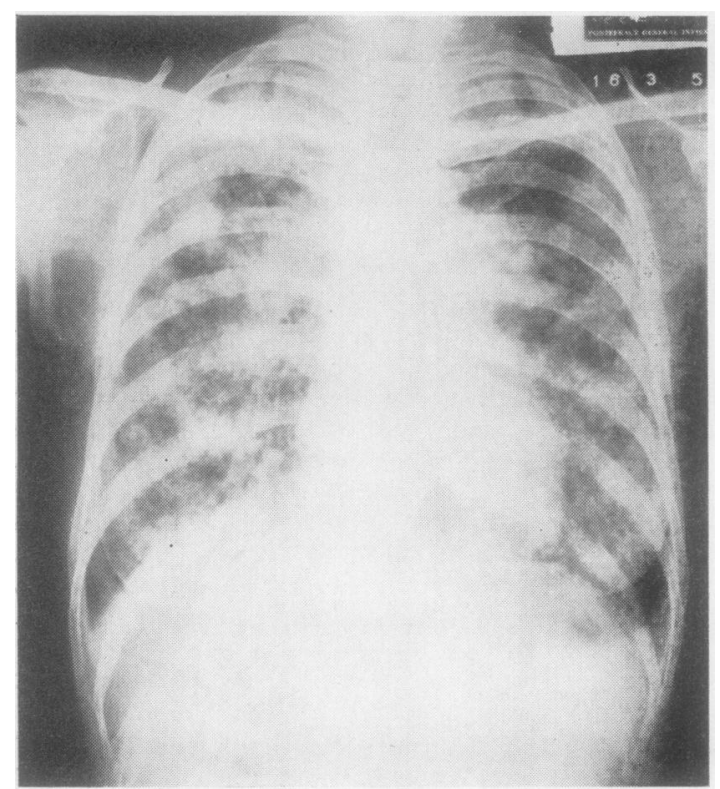

FIG. 2.-Radiograph of the chest in March, 1956, showing diffuse coarse nodulation of the lung fields associated with areas of massive fibrosis.

(polymorphonuclears $56 \%$, eosinophils $2 \%$, lymphocytes $32 \%$, monocytes $10 \%$ ). The sedimentation rate (Wintrobe) was $3 \mathrm{~mm}$. in the first hour. Acid phosphatase 3 K.-A. units, inorganic phosphate (as P) $3 \mathrm{mg}$. per $100 \mathrm{ml}$. ; plasma proteins $6.8 \mathrm{~g}$. (albumin 4.9 g., globulin 1.9 g.) per $100 \mathrm{ml}$. Blood Wassermann and Kahn tests were negative. 'The electrocardiogram was normal.

Repeated examinations of the sputum for tubercle bacilli were negative. The organisms in the sputum were scanty and those predominating were nonhaemolytic streptococci, $N$. catarrhalis, and yeasts. No beryllium was detected spectroscopically in a 24hour specimen of urine.
SkIN TESTS.--Patch tests were performed with क्षे $1 \%$ solution of beryllium sulphate and a $1 \%$ solution of beryllium nitrate. A square of ribbon gauze moistened with one of the solutions was applied to the skin. A similar square moistened with the othero solution was applied about $1 \frac{1}{2}$ in. distant. The two squares were then covered with cellophane which waso held in position by adhesive strapping. At the end of 48 hours the strapping was removed. There waso a marked reaction to each solution in the form of anç area of papules and vesicles, with mild erythema The two areas were almost confluent (Fig. 3). The eczematous reaction subsided after 14 days and even $\frac{0}{3}$ tually left small superficial scars (Fig. 4).

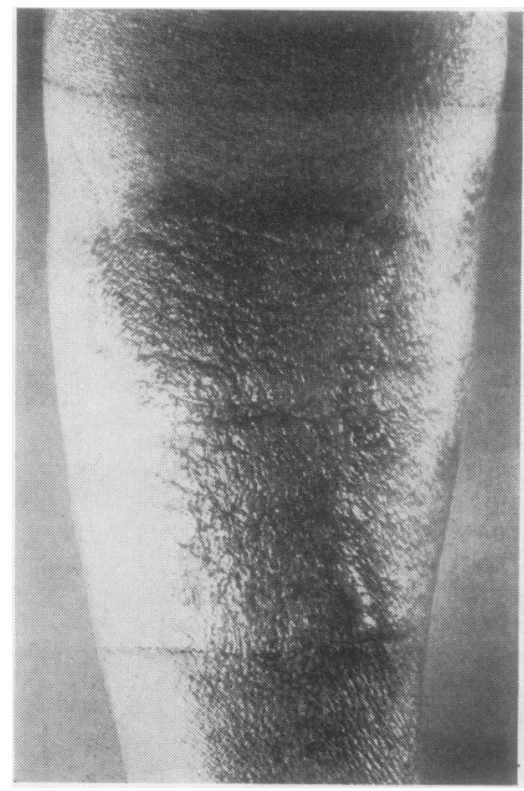

Fig. 3.-Patch tests with beryllium salts 48 hours after application. 


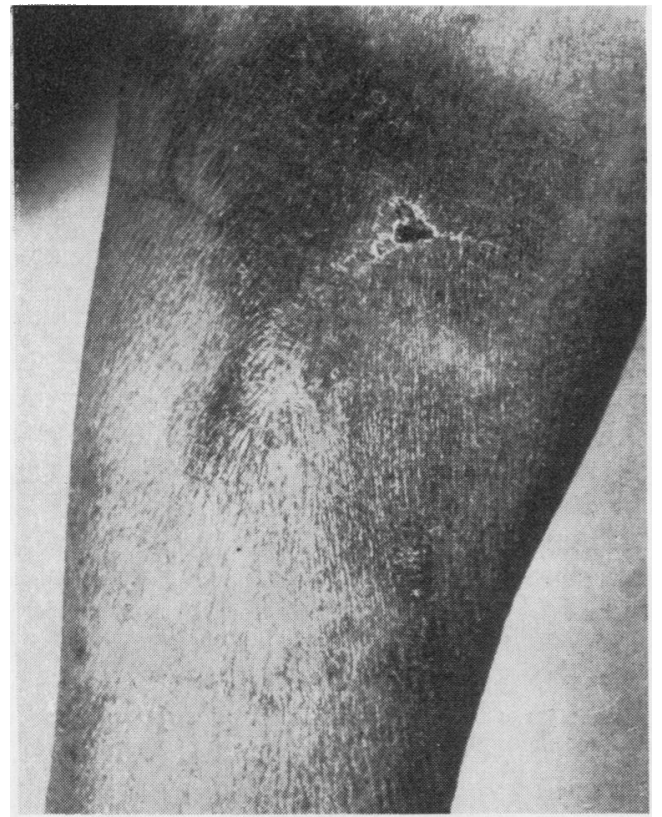

FIG. 4.-Patch tests two weeks after application.

RESPIRATORY FUNCTION.-Studies of respiratory function supported the clinical and radiological concept of a severe degree of diffuse pulmonary fibrosis. The vital capacity measured only $1,000 \mathrm{ml}$. (44\% of predicted vital capacity). The total lung volume was $3,500 \mathrm{ml}$. of which $70 \%$ was residual air $(2,460 \mathrm{ml}$.).
The maximum ventilatory capacity performed at 45 breaths per minute was 32 litres $(50 \%$ of predicted volume). Spirograms of forced inspiratory and expiratory phases of respiration showed moderate reduction in the rate of air flow, but there was no evidence of air trapping. The mixing efficiency of the lungs was slightly impaired. The oxygen saturation of resting arterial blood was $89 \%$. No demonstrable change cccurred during moderate exercise, but $100 \%$ saturation was obtained with oxygen inhalation. The carbon dioxide tension of arterial blood was normal and the $p \mathrm{H}$ was 7.41 .

SkIN Biopsy.-The lesion on the left forearm was excised. Microscopically the section revealed some thinning of the epidermis with a little increase in keratin. Several well-defined granulomata were present in the corium and some of these showed small areas of central necrosis. A few contained multinucleated giant cells. The lesions were surrounded by lymphocytes and separated by loose fibrous tissue. No tubercle bacilli were demonstrated and there were no birefringent crystals. The picture was that of an active granulomatous lesion with some resemblance to that seen in sarcoidosis (Fig. 5).

\section{Discussion}

Chronic beryllium poisoning is a remarkable condition in that there appears to be no direct relationship between the degree of exposure to beryllium compounds and the incidence of the disease. American reports have shown that when a large number of individuals are apparently ex-

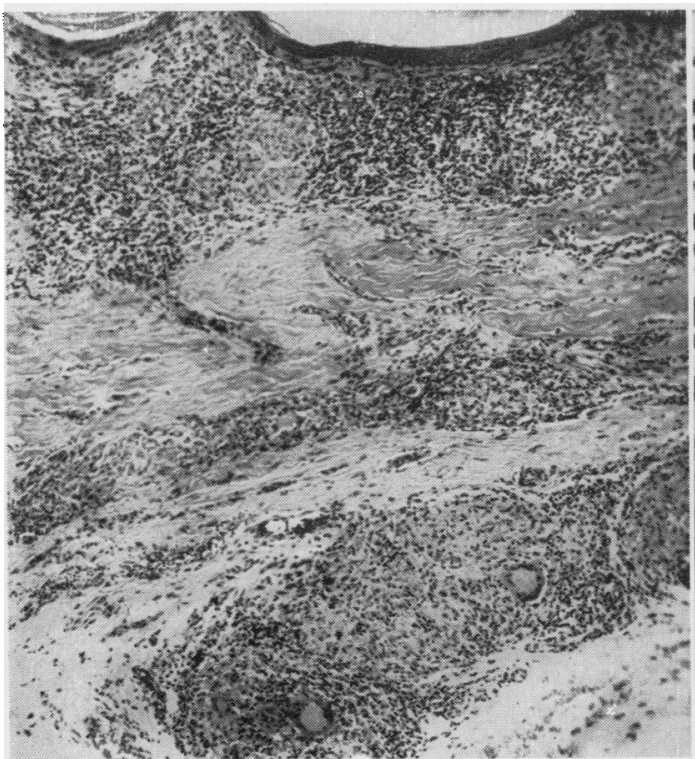

A

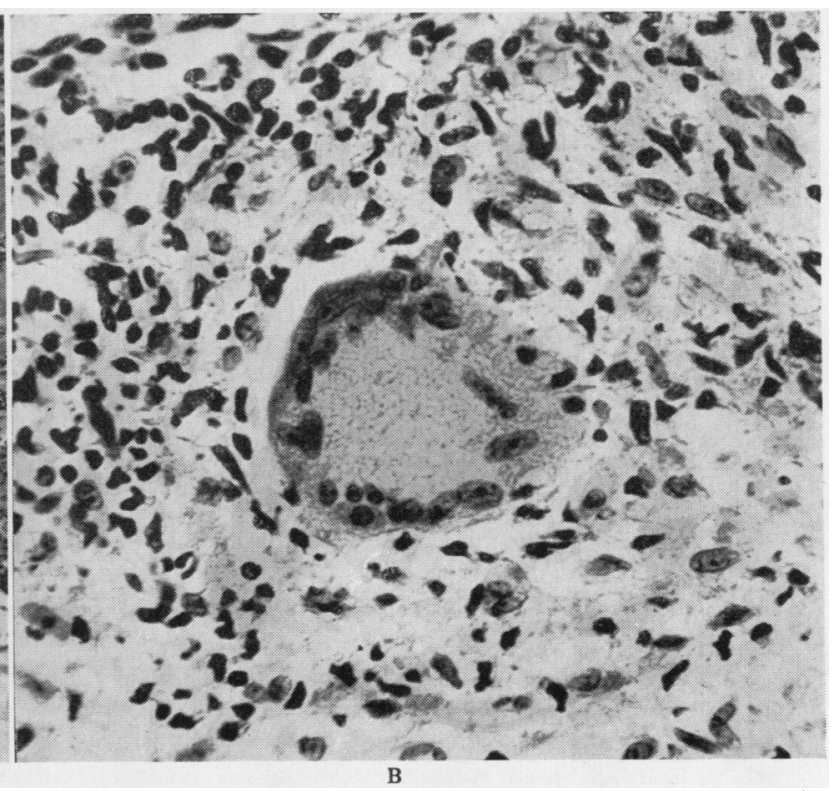

FIG. 5-Microscopical section of excised skin lesion showing granulomatous change in the corium. A. Haematoxylin and eosin, $\times$ 65. B. Section of follicle with giant cell, haematoxylin and eosin, $\times 440$. 
posed to the same hazard, only a small proportion actually develop lesions which have the microscopical character of the condition. Spectroscopic examinations of the urine of such workers in contact with beryllium salts have demonstrated the excretion of beryllium at the time of and for some period after exposure without any subsequent manifestation of the disease. In addition, there are records of patients who showed the classical picture of chronic beryllium poisoning without any direct or close exposure to the fumes. Such patients include those who lived at a considerable distance from the factory where beryllium was being used (neighbourhood cases) and those whose only exposure was that due to direct contact from washing the linen of employees at the factory. Agate (1948) observed that it is the patient with unusual susceptibility rather than the worker with long exposure who develops the disease.

Unfortunately the smallest amount which may be toxic for any one individual is still uncertain, but is probably very minute. The duration of exposure which might be termed "safe" is also unknown.

It is generally assumed that inhalation of dust or fumes causes the systemic disease and that the subcutaneous granulomata are of traumatic origin. Sneddon's (1955) case, which occurred in a worker who was employed solely in shearing strips of beryllium copper, does not support this view, for in this instance the production of dust was negligible. Furthermore, it is clear that all skin lesions do not necessarily occur at the site of known previous injury; the granulomata may erupt spontaneously alongside more definite linear lesions due to old lacerations. Although the lungs are normally the route by which beryllium enters the body, it is also possible that the skin may provide an adequate pathway on occasion.

Numerous descriptions of individual cases and wider surveys of all workers exposed to the same hazard and followed carefully over a long period have enabled a general picture to be pieced together. An analysis of all these reports indicates that the chronic form of beryllium poisoning should be regarded as a generalized disease in which the lungs and skin bear the brunt of the damage. Collected post-mortem studies, however, have established that lesions may occur also in the liver, spleen, kidneys, myocardium, pleura, and lymph nodes. Laboratory studies have shown disturbances in nitrogen and calcium metabolism and an increase in serum protein with a relative increase in gamma globulin.
Since the pulmonary and skin manifestations of the chronic disease may be mimicked by a number of unrelated disorders, particularly sarcoidosis, it is important to establish strict criteria for the diagnosis of the disease. Accepted cases must have a history of exposure to beryllium. Occa- $\propto$ sionally such a hazard may not at first be apparent $\stackrel{0}{\%}$ if the patient has not been directly engaged in $\vec{\circ}$ work involving the metal, or if after exposure he has moved some distance to a part of the country where no form of industrial work is carried out. It is desirable to have evidence that the beryllium has entered the body, and for this spectroscopic $\vec{\omega}$ examination of the urine or of affected tissues may $\overrightarrow{.}$ be helpful. Even if proof of entry is established, 8 the subject may not be suffering from beryllium 을 poisoning, for this depends essentially upon an abnormal reaction to beryllium. The existence of 3 an abnormal response is suggested if the lesions of the skin and lungs or elsewhere in the body show the characteristic features of a granuloma on $\vec{c}$ microscopy. Confirmation is obtained if there is 9 a marked reaction to the patch testing of the skin with weak solutions of beryllium salts. The great value of this test is that it shows that the subject has become sensitized to the metal.

Curtis introduced the skin test in 1951 and his $\mathbb{D}$ report has been followed by others (DeNardi and others, 1953 ; Van Ordstrand, 1954) which have confirmed the specificity of the skin patch test. This claim is also supported by Sneddon (1955), who referred to investigators in this country who have made the test on a large number of patients, including cases of sarcoidosis, without obtaining a $x$ false positive result. Sneddon also observed that biopsy of the skin lesion resulting from the patch test a few weeks after it was performed reveals histological features of a sarcoid-like reaction.

Some critics of the test (Hardy, 1956) state that, 음 as beryllium is known to be a skin sensitizer, there $\frac{D}{O}$ must be some doubt as to the specificity in workers known to have been exposed to airborne N beryllium compounds. This objection would be valid if examples of a positive reaction in such $\mathrm{N}$ workers not suffering from beryllium poisoning $\omega$ were to be found; so far none has been recorded.

A more serious criticism of the procedure is that it is liable to provoke a violent reaction in $\stackrel{\infty}{\Phi}$ the lungs. It is probable that such an event did oscur in Sneddon's case. For this reason it is imperative to use only a dilute solution of the salts for the tests. It may be remarked that no $\frac{\rho}{1}$ small advantage of the test is the ease of $\varrho$ performance. 
The natural evolution of the disease is variable, but the usual course is one of progressive pulmonary fibrosis leading to death from respiratory or cardiac failure. It is possible that in a few cases cure will be spontaneous. The outlook will depend upon the stage of the disease when it is first recognized, but once extensive and irreversible fibrosis has been established in the lungs the ultimate prognosis is grave.

Treatment of chronic beryllium poisoning is unsatisfactory. The immediate step is to remove the patient from all possible contact with any form of beryllium. It is well recognized that in hypersensitive states even the slightest exposure may result in a violent reaction and exacerbation of symptoms. In view of the knowledge that beryllium may be deposited in a variety of tissues, including the bones, and perhaps be released from these structures from time to time, many attempts have been made to find an agent which can eliminate all traces of the compound from the body, or one that renders such compounds inert by procuring their chemical combination with some other innocuous substance. Dimercaprol and other agents have been employed without benefit.

Some improvement has followed treatment with either corticotrophin or cortisone, but there are reports of comparable cases in which little or no objective benefit occurred. There have also been instances of severe relapse following withdrawal of these drugs. Unless the symptoms are disabling and the course rapidly progressive, it would seem wiser to withhold these drugs and advise the patient to seek some light employment which throws no additional strain on the lungs or heart.

Many cases of chronic poisoning are probably recognized late in the disease and at a time when the radiological features are apparently consistent with advanced fibrosis. The microscopical features of biopsy material obtained from lung lesions at this phase, or indeed from skin lesions 10 or more years after exposure, suggest that the disease is still in an active and partly reversible stage. This is also supported by the reaction which may occur in the lungs following patch testing, if strong solutions of beryllium salts are used. In view of these observations, any therapy which is known to have an effect on abnormal sensitivity or has been shown to help the resolution of chronic cellular reactions is worthy of consideration in a progressive case.

In spite of all efforts, many cases pursue a slow and inexorable deterioration punctuated by exacer- bations from respiratory infections and ultimately from one or more attacks of heart failure. At such times antibiotics and the usual remedies for congestive cardiac failure may prolong life, and at the present time they are the only certain methods of giving relief in this distressing condition.

\section{SUMMARY}

A middle-aged woman was exposed for two years to a high concentration of zinc beryllium silicate phosphors used in the manufacture of fluorescent lamps. During this period she sustained a number of lacerations from broken tubes. She left the neighbourhood of the factory and five years later developed a persistent unproductive cough, chest pains, and exertional dyspnoea. Eventually she sought medical advice, and a diagnosis of chronic beryllium poisoning was made 10 years after her last exposure. She was found to have moderate respiratory insufficiency, radiographic evidence of a diffuse granulomatous and fibrotic process in the lungs, splenomegaly, and a number of sarcoid-like granulomata on the forearm, knees, and ankles. Her skin gave a strongly positive reaction to a patch test with a dilute solution of a beryllium salt. The observation that all patients with chronic beryllium poisoning show positive patch tests is thought to support the view that the development of a hypersensitive state is an essential feature in the pathogenesis of the disease.

Our thanks are due to Miss Beryl Snowden, of the City General Hospital, Sheffield, who carried out the respiratory function tests, and to Mr. Lambourne for the photomicrography. We wish to acknowledge the help we received from many colleagues, particularly from Dr. W. D. Buchanan, H.M. Medical Inspector of Factories, Leeds, from Dr. P. Tyson Davidson, medical officer, B.T.H. Works, Rugby, for details of the occupational history, and from Dr. I. B. Sneddon, of the Royal Infirmary, Sheffield.

\section{REFERENCES}

Agate, J. N. (1948). Lancet, 2, 530.

Curtis, G. H. (1951). A.M.A. Arch. Derm. Syph., 64, 470.

DeNardi, J. M., Van Ordstrand, H. S., Curtis, G. H., and Zielinski, J. (1953). A.M.A. Arch. industr. Hyg., 8, 1.

Hardy, H. L. (1956). Amer. Rev. Tuberc. 74, 885.

- - and Tabershaw, I. R. (1946). J. industr. Hyg., 28, 197.

Rogers, W. N. (1957). Lancet, 2, 267.

Sneddon, I. B. (1955). Brit. med. J., 1, 1448.

Van Ordstrand, H. S. (1954). A.M.A. Arch. industr. Hyg., 10, 232. Hughes, R., DeNardi, J. M., and Carmody, M. G. (1945). J. Amer. med. Ass., 129, 1084.

Weber, H. H., and Engelhardt, W. E. (1933). Zbl. Gew.-Hyg., 20 (n.s.10), 41 . 